\title{
Desempenho ocupacional de adolescentes diagnosticados com transtorno de conduta do centro de atenção psicossocial infantojuvenil
}

\author{
Occupational performance of diagnosed teens with conduct disorder of the psychosocial care center \\ for children and adolescents \\ Desempeño ocupacional de adolescentes diagnósticos con trastorno de conducta en el centro de \\ atención psicosocial infanto-juvenil
}

Recebido: 09/09/2021 | Revisado: 15/09/2021 | Aceito: 20/09/2021 | Publicado: 22/09/2021

\author{
Lucas Lima de Medeiros \\ ORCID: https://orcid.org/0000-0003-4506-7500 \\ Instituto de Medicina Integral Professor Fernando Figueira, Brasil \\ E-mail: lucasmedeirosto@gmail.com \\ Maria Luiza Morais Regis Bezerra Ary \\ ORCID: https://orcid.org/0000-0002-8376-2224 \\ Universidade Estadual de Ciências da Saúde de Alagoas, Brasil \\ E-mail: maria.ary@uncisal.edu.br \\ Adriana Reis de Barros \\ ORCID: https://orcid.org/0000-0002-5404-9737 \\ Universidade Estadual de Ciências da Saúde de Alagoas, Brasil \\ E-mail: adriana.barros@uncisal.edu.br
}

\begin{abstract}
Resumo
A participação social é um fenômeno complexo que necessita de estudos mais aprofundados e discussões críticas dentro do cenário científico da Atenção à Saúde Mental de crianças e adolescentes, desta forma, compreende-se que o presente estudo contribui para o avanço do conhecimento em relação aos adolescentes com transtorno de conduta em relação a sua participação social. O estudo tem como objetivo verificar as principais alterações no desempenho ocupacional no que se refere à participação social dos adolescentes com transtorno de conduta de um Centro de Atenção Psicossocial Infantojuvenil no Nordeste do Brasil. Trata-se de estudo transversal de caráter qualitativo. Para o seu desenvolvimento foi utilizado um questionário semiestruturado que se preocupa a investigar três grandes polos de participação social desses adolescentes, que seriam: o grupo familiar, a comunidade e a escola. O questionário foi aplicado com pais ou responsáveis de adolescentes com transtorno de conduta. Os resultados mostraram que houve alteração significativa no desempenho ocupacional no que se refere à participação social dos participantes desse estudo, demonstrando que os profissionais de saúde precisam compreender a importância da participação social nos CAPSis com esses jovens, familiares e comunidade para minimizar o sofrimento dessa clientela e de seus familiares, favorecendo a inclusão social e diminuindo o preconceito da sociedade para com essas crianças e adolescentes.
\end{abstract}

Palavras-chave: Transtorno de conduta; Saúde mental; Desempenho ocupacional.

\begin{abstract}
Social participation is a complex phenomenon that needs further studies and critical discussions within the scientific scenario of Mental Health Care for children and adolescents, thus, it is understood that this study contributes to the advancement of knowledge in relation to adolescents with conduct disorder in relation to their social participation. The study aims to verify the main changes in occupational performance with regard to the social participation of adolescents with conduct disorder at a Psychosocial Care Center for Children and Youth in Northeastern Brazil. This is a crosssectional qualitative study. For its development, a semi-structured questionnaire was used, which is concerned with investigating three major poles of social participation of these adolescents, which would be: the family group, the community and the school. The questionnaire was applied to parents or guardians of adolescents with conduct disorder. The results showed that there was a significant change in occupational performance with regard to the social participation of the participants in this study, demonstrating that health professionals need to understand the importance of social participation in CAPSis with these young people, their families and the community to minimize the suffering of this clientele and their families, favoring social inclusion and reducing society's prejudice towards these children and adolescents.
\end{abstract}

Keywords: Conduct disorder; Mental health; Occupational performance.

\section{Resumen}

La participación social es un fenómeno complejo que requiere de mayores estudios y discusiones críticas dentro del 
escenario científico de la Atención en Salud Mental para niños y adolescentes, por lo que se entiende que este estudio contribuye al avance del conocimiento en relación a los adolescentes con trastorno de conducta en relación a su participación social. El estudio tiene como objetivo verificar los principales cambios en el desempeño ocupacional con respecto a la participación social de adolescentes con trastorno de conducta en un Centro de Atención Psicosocial para Niños y Jóvenes en el Nordeste de Brasil. Este es un estudio cualitativo transversal. Para su desarrollo se utilizó un cuestionario semiestructurado, el cual se preocupa por investigar tres grandes polos de participación social de estos adolescentes, que serían: el grupo familiar, la comunidad y la escuela. El cuestionario se aplicó a padres o tutores de adolescentes con trastorno de conducta. Los resultados mostraron que hubo un cambio significativo en el desempeño ocupacional con respecto a la participación social de los participantes en este estudio, demostrando que los profesionales de la salud necesitan comprender la importancia de la participación social en CAPSis con estos jóvenes, sus familias y la comunidad para minimizar el sufrimiento de esta clientela y sus familias, favoreciendo la inclusión social y reduciendo los prejuicios de la sociedad hacia estos niños, niñas y adolescentes.

Palabras clave: Desorden de conducta; Salud mental; Desempeño ocupacional.

\section{Introdução}

O Transtorno de Conduta (TC) é um dos transtornos mentais mais notificados na infância e adolescência, se mostrando como uma das principais causas de encaminhamento para os Centro de Atenção Psicossocial Infantojuvenil (Dias L., 2012). Com isso, o TC pode causar diversas alterações nas habilidades de desempenho quando relacionada à participação social e produtividade, tendo perdas significativas nas suas execuções (Bordin, \& Offord, 2000).

Esse transtorno é o conjunto de problemas psicoemocionais que ocorrem na fase de formação da personalidade de crianças e adolescentes. Atualmente não existe etiologia que comprove a causa biológica do mesmo, em contrapartida, seu principal causador podem ser os conflitos familiares. É um dos transtornos mais frequentes na infância e um dos maiores motivos de encaminhamento ao CAPSi (Dias, 2012)

O Centro de Atenção Psicossocial infanto juvenil (CAPSi) faz parte da rede de atenção psicossocial, sendo um serviço substitutivo que atende crianças e adolescentes com transtornos mentais graves e persistentes, dentre eles temos o transtorno de conduta (TC) como um dos principais transtornos atendidos neste serviço e que impactam a vida dos jovens, familiares e algumas vezes da comunidade.

Essas crianças e adolescentes apresentam um comportamento singular, como dificuldades de aceitar regras e limites, gostar de atividades perigosas e violentas, conflito com a lei e uso de substâncias ilícitas (Codea, \& Beresford, 2004). Conforme Squillaci, \& Benoit, (2021), que os jovens com transtornos comportamentais, apresentam um risco aumentado de desenvolver comportamentos anti-sociais graves e persistentes na idade adulta, que pode trazer diversas problemáticas ocupacionais no futuro.

Podem apresentar em muitos casos o comportamento antissocial, através de ações agressivas, impulsivas e às vezes violentas, que infringem as regras, convenções e códigos estabelecidos de uma sociedade, tais como leis que apoiam os direitos pessoais e de propriedade, podendo envolver características de crueldade física com as pessoas e com animais, mentiras e rompimentos de promessa, roubos, estupros e homicídios (American Psychiatric Association, 2013).

Os sintomas podem persistir até a idade adulta, caso essa criança e ou adolescente não receba o apoio psicossocial necessário para conseguir se adaptar aos espaços sociais adequados a sua faixa etária, desta forma, pode haver fortes consequências do comportamento, como conflito entre os casais, abandonos e demissões de empregos, criminalidade gerando prisão, por furtos, assassinatos, estupros e violências. Há uma maior incidência em indivíduos do sexo masculino do que no sexo feminino, apresentando características precoces no sexo que tem maior prevalência (Dias 2012; 2012; Bordin, Offord, 2000).

O diagnóstico é feito seguindo as especificações do Manual de Diagnóstico e Estatística de Transtornos Mentais (Diagnostic and Statistical Manual of Mental Disorders- DSM-V), sendo emitido por um médico psiquiatra ou neuropsiquiatra, e é classificado por gravidade; leve, para pessoas que cometeram danos de conduta leves; moderado, quem cometeu um número considerado de danos; grave, quem cometeu danos de condutas que fere diretamente ao outro (Machado, Caye, Frick, \& Rohde, 2015). 
O TC pode trazer complicações nas realizações dos papéis ocupacionais e no desempenho ocupacional desse adolescente. $\mathrm{O}$ desempenho ocupacional são as habilidades de realizar rotinas e desempenhar papéis e tarefas com o objetivo de autocuidado, produtividade, e participação social em resposta às demandas do sujeito. Refere-se à capacidade de realizar tarefas ocupacionais de maneira satisfatória e apropriada para o estágio de desenvolvimento, cultura e ambiente do indivíduo (Chapparo, \& Ranka, 1997).

As ocupações são atividades humanas, que fazem parte da vida cotidiana do sujeito, sendo subdivididas em: atividades de vida diária (AVDs), atividades instrumentais de vida diária (AIVDs), descanso e sono, educação, trabalho, brincar, lazer e participação social.

Assim, a participação social é definida como:

"A inter-relação de ocupações para apoiar o envolvimento desejado em atividades comunitárias e familiares, bem como aquelas que envolvem pares e amigos "(Gillen \& Boyt Schell, 2014, p 607 Apud AOTA, 2015).

Desse modo, este estudo se propõe a verificar as principais alterações no desempenho ocupacional no que se refere à participação social dos adolescentes diagnosticados com transtorno de conduta do Centro de Atenção Psicossocial Infantojuvenil de Maceió - AL, visando conhecer as dificuldades desses jovens para um cuidado integral, humanizado, voltado a clínica ampliada que possa enfrentar a estigmatização que esses jovens enfrentam.

\section{Metodologia}

Trata-se de um estudo transversal, descritivo de caráter qualitativo. A pesquisa foi desenvolvida no Centro de Atenção Psicossocial Infantojuvenil, Maceió - AL. O artigo é resultante de um projeto de pesquisa, encaminhado para o Comitê de Ética em Pesquisas com Seres Humanos da Universidade Estadual de Ciências da Saúde de Alagoas (UNCISAL).

No primeiro momento foi realizado uma busca no universo de prontuários no CAPSi, de adolescentes entre doze (12) a dezoito (18) anos incompletos com transtorno de conduta que fazem parte de oficinas terapêuticas, logo após a busca dos prontuários, foram identificados dez (10) prontuários de forma aleatória. Foram excluídos da pesquisa prontuários de usuários com déficit cognitivo importante que limite o desempenho ocupacional, e que não participem de oficinas terapêuticas, e que estejam no serviço há menos de três (3) meses.

No segundo momento, foram convidados os responsáveis dos adolescentes para participar da pesquisa. A coleta foi realizada com sete (7) responsáveis. No terceiro momento se deu a obtenção dos dados, através de um questionário semiestruturado construído pelos pesquisadores e aplicado com os responsáveis dos adolescentes, onde o mesmo possibilita o conhecimento das principais alterações no desempenho ocupacional quando se refere às habilidades de participação social. O questionário se preocupa em investigar três grandes polos de participação social dos adolescentes, que seriam: o grupo familiar, a comunidade e a escola.

O estudo foi realizado no período de julho e setembro de 2019, seguindo os critérios éticos recomendados. Após a aquisição dos dados, foi realizada a análise qualitativa. Segundo Fernandes (1991), a análise qualitativa vai se caracterizar pela compreensão e interpretação das falas dos participantes da pesquisa, em comparação ao campo teórico usado pelo pesquisador.

De acordo com Diehl e Tatim, (2004), a técnica qualitativa consegue descrever de forma mais satisfatória a complexidade do estudo, deixando o processo da pesquisa mais dinâmico, possibilitando o aprofundamento e compreendendo a singularidade do problema estudado. 
Sendo assim, a análise dos dados foi construída através do esquema de Alves \& Silva (1992), que divide a análise qualitativa em três grandes momentos: 1) análise dos dados em relação ao problema da pesquisa, 2) análise dos dados em relação ao campo teórico e 3) que seria a interpretação geral sobre os dados reais do estudo.

\section{Resultados e Discussão}

Com base na construção do questionário e da análise do material produzido nas respostas, foram elaboradas três categorias para melhor aprofundar a discussão a seguir, sendo eles: Participação social: Família, Participação social: Escola, Participação social: Comunidade. Porém antes da discussão das categorias, faz-se necessário a apresentação de uma caracterização da amostra.

O estudo foi dividido em duas fases, na primeira foram identificados 24 (100\%) crianças e adolescentes com TC, 12 (50\%) atendeu os critérios de inclusão da pesquisa, e foi aplicado o questionário com apenas 7 (58,33\%) responsáveis. Em seguida foi utilizado o questionário de sete (7) responsáveis.

Com base no qustionário foi possível levantar as seguintes informações básicas: 4 eram do sexo masculino e 3 eram do sexo feminino; a idade varia de 12 a 14 anos, sendo que 4 om idade de 13 anos, 1 om idade de 12 anos, 1 com idade de 14 anos e 1 com idade de 17 anos. Em relação à escolaridade, 2 frequentam o $5^{\circ}$ ano, 2 frequentam o $6^{\circ}$ ano, 1 frequenta o $9^{\circ}$ ano, 1 frequenta a escola, contudo o responsável não sabe informar o ano escolar e 1 o responsável retirou da escola.

\subsection{Participação social: Família}

A função social da família transcende a função econômica, para a proteção, afeto, segurança e colaborando para o desenvolvimento da subjetividade, com a intenção de proporcionar uma melhor interação no meio social, estruturando o sujeito na sua formação e socialização (Maluf, A., 2010). Assim, nesse tópico do estudo serão discutidos os principais dilemas que impedem um desempenho significativo no que se refere à participação social desses adolescentes dentro do grupo familiar.

Nas perguntas que abordam o comportamento dos adolescentes dentro de casa com os membros da família, pode-se afirmar que uma das principais dificuldades é a oscilação de humor, no qual, o adolescente sai de um comportamento "calmo", para um agressivo e/ou violento. Então os profissionais dos CAPS que aturam com o público com esse tipo de questão, precisam trabalhar com o jovem como exteriorizar suas emoções e sentimentos para que deixem de serem vistos com um olhar desviante e possam ser acolhidos pela sua família e comunidade.

Quanto o relacionamento com a família, as respostas foram,

"Péssima, ele quando se estressa pega tudo que tiver na frente pra bater". (Participante 03)

"Não é muito boa, ele quer uma coisa e eu outra, ele é violento as vezes". (Participante 04)

"Ela é muito teimosa, não me obedece". (Participante 05).

"Se deixar ela briga o tempo todo". (Participante 07).

Já em relação ao comportamento desses adolescentes,

"Ele é muito agressivo em casa [...] ele já pegou a faca pra matar o amigo do pai dele, porque ele fez uma brincadeirinha que ele não gostou”. (Participante 03).

"Ele não se comporta, ele é agressivo, violento e muito estressado". (Participante 04).

"Ela é muito respondona, quando era mais nova, batia, jogava as coisas". (Participante 05).

"Pra mim, assim, tá dificill". (Participante 07). 
Nessas falas observamos a importância do apoio familiar para que a mesma seja um suporte positivo para estas crianças, e que a família necessita de uma escuta qualificada com orientação a respeito da melhor forma de lidar com esses jovens, sem enfraquecer os vínculos familiares. É irrefutável que a adolescência é marcada por diversas transformações, biológicas e sociais, assim, mudanças de comportamentos e não aceitação de regras sociais é típico desse período, já em relação ao adolescente com esse sofrimento mental, esse comportamento traz prazer e satisfação em um nível de desorganização social (Agostini, \& Santos, 2017).

Os comportamentos agressivos/violentos e desafiadores são adotados constantemente contra as pessoas que representam papéis de autoridade sobre o adolescente, principalmente familiares. Tais adolescentes estão sempre resistentes à aceitação de regras, além de perder o controle facilmente em caso de ser frustrada em suas intenções (Barletta, 2011; Pinheiro, et al, 2004).

Desse modo, esses comportamentos desafiadores e agressivos, por vezes podem afastar o adolescente de estabelecer uma relação afetiva e harmônica com seus responsáveis, dificultando na criação e manutenção da participação social dos mesmos.

Outras respostas convergentes do questionário foram à falta de afeto e empatia dos adolescentes para com os responsáveis ou animais domésticos. De forma geral, todos os responsáveis relataram dificuldades de conversar e estabelecer um diálogo com os adolescentes.

Além disso, todos os responsáveis falam também da falta de demonstração de afeto dos adolescentes com os membros familiares, como: abraço, beijo e carinho. E com isso, os adolescentes que têm ou tinham animais domésticos dentro de casa tem histórico de violência com o animal.

“[...] ela não gosta de abraços, não dá carinho, não fala sobre sentimentos. [...] Ela tinha um gato, ela arrancou os dentes do gato com o alicate e ficou olhando e rindo". (Participante 02).

“Às vezes, mas ela se estressa com qualquer pessoa, machuca, bate, e pega tudo que tiver na frente, já pegou até a faca para irmã dela.". (Participante 03).

"Já matou um cachorro dele, acreditamos que foi ele, porque ele espancou ele [...] os gatos e cachorros tem medo dele". (Participante 06)

A falta de afeto e empatia e a presença de um comportamento violento/agressivo é um comportamento típico de um adolescente com transtorno de conduta, porém, as relações sociais só acontecem nas trocas emocionais e intersubjetivas, para com isso, alcançar um bom relacionamento social (Codea, J. \& Beresford, H., 2004; Leitão, S., Fortunato, G. \& Freitas, A., 2006).

A empatia e afeto é uma das principais características para uma criação de uma relação social efetiva e determinante na efetivação de uma boa participação social, tendo em vista isso, pode-se afirmar que essa habilidade de desempenho é prejudicada de forma significativa no adolescente com TC, com isso, a importância da equipe multiprofissional nos CAPS para dar esse suporte necessário para essa clientela superar essas dificuldades (Araújo et al., 2017).

Ainda segundo ao autor, a afetividade torna o sujeito mais seguro de si, demonstrando mais interesse nas atividades sociais e cotidianas, apresentando mais proximidade nas relações com outras pessoas, inclusive dentro do grupo familiar $\mathrm{O}$ vínculo estabelecido na vida de indivíduos com TC é um fator importante, pois, um adolescente sem vínculo familiar apresenta de forma mais evidente comportamentos desviantes, como violência, quebra de regras e agressividade, assim as famílias devem saber como lidar com os adolescentes e tentar resolver tais conflitos (Dias, L., 2012).

Ainda em relação ao comportamento dos adolescentes, os responsáveis afirmam a falta de medo desses adolescentes em quebrar as regras, os comandos e em alguns casos até colocar em risco a sua própria vida ao se alocar em situações extremamente perigosas. Outro comportamento presente desses adolescentes é o ato de mentir, segundo os responsáveis a 
mentira é uma ação típica dos adolescentes e isso pode variar da mentira mais simples até a mais complexa.

Dentro das respostas do questionário, apenas quatro (4) relatam o ato de roubo dentro ou fora de casa, contudo, o que mais implica nessas respostas é a falta de confiança que os responsáveis direcionam para os adolescentes e em tudo que os mesmos falam.

"Às vezes, ele rouba dinheiro de casa [...] uma vez ele roubou um celular para conseguir dinheiro". (Participante 04).

"Rouba dentro de casa e no mercadinho [...] tem que ficar vigiando". (Participante 07).

Sendo assim, comportamentos marcados pela impulsividade, agressividade, violência, antecipação, agitação, mentiras, furtos, desrespeito a limites, brigas e hostilidade nos relacionamentos dificultam a interação com o ambiente, geram conflitos e frequentemente ocasionam o rompimento nas interações, principalmente na relação familiar (Ferriolli, Marturano, \&Puntel, 2007).

Ainda em relação às respostas do questionário, apenas três (3) mostraram envolvimento com o conselho tutelar, sendo que um dos principais motivos é a escola, em relação ao ato de violência com os outros colegas.

"Sim, porque ela ameaçou a professora dizendo que ia chamar os caras do bom parto, aí a escola queria tirar ela da escola, aí eu fui procurar o conselho para não tirar ela da escola". (Participante 01).

"Sim, ele vivia muito na rua, ai eu fui pedir ajuda ao conselho tutelar e não ajudou”. (Participante 04).

"Sim, o colégio chamou o conselho tutelar porque ele brigou com um menino [...] quase quebrou a cabeça do menino, e foi expulso do colégio". (Participante 06).

Já em relação ao uso de álcool e drogas, nenhuma resposta mostra que os adolescentes estão fazendo uso, da mesma forma que as mesmas também não estão praticando o ato sexual é apenas um (1) o responsável visualizar aumento da libido sexual do adolescente.

"Ela só fala em namorar com um rapaz [...] ela só ia para escola para ficar de papinho com os meninos [...] peguei ela falando no zap com um menino, mandando fotos pornô, agora não deixo mais". (Participante 07).

Pode-se dizer que as principais problemáticas para um desempenho ocupacional significativo em relação à participação social dos adolescentes com transtorno de conduta dentro do grupo familiar é a presença de um comportamento agressivo e ou violento, a falta de empatia e afeto, a não aceitação de regras e comandos e a mentira.

Destaca-se que a família é o principal pilar das relações sociais do sujeito, e garantindo noções dignas de desenvolvimento afetivo, emocional e social, fazendo com que o mesmo se sinta parte desse grupo familiar, vivenciando o afeto, a empatia, o respeito, a confiança, a cumplicidade, o carinho e o amor, de forma a desenvolver condições de estabilidade emocional (Aranha, M., 2000).

A família é a alicerce da construção psicossocial do indivíduo, pois quando o sujeito convive em uma família negligente, isso pode trazer consequências negativas em sua formação social e afetiva, o qual corrobora com a ideia de Santos et al, (2021) quando afirma que o relacionamento familiar é um fator de grande influência quanto às características e comportamento do indivíduo. Por isso, é importante que a família participe positivamente durante o desenvolvimento do adolescente, para que o mesmo consiga estabelecer efetivamente sua participação social dentro do grupo familiar e em outros espaços (Melo, D. at al, 
2016).

\subsection{Participação social: Escola}

A interação social se inicia na família, posteriormente na escola, onde há contato entre diferentes sujeitos, com pensamentos, reflexões, vivências diferentes da que estar habituado, começando a conhecer, aprender e a conviver com essas diferenças entre outros. Assim a escola oferece mudanças advindas do contexto social favorecendo diretamente na construção e na participação social (Wieczorkievick, \& Baade, 2020).

Vale ressaltar que educação é uma das principais ocupações dos adolescentes, com isso, esse tópico do estudo irá se preocupar em discutir principais problemáticas que impedem a participação social desses adolescentes dentro do ambiente escolar.

O questionário aplicado se preocupa em investigar o comportamento dos adolescentes com transtorno de conduta em relação a sua interação e participação dentro da escola, com os outros alunos, com os professores e funcionários, como também seu desempenho escolar.

Como descrito anteriormente, apenas seis (6) dos sete (7) adolescentes estão inseridos na escola, cursando o ensino fundamental, porém, todos os adolescentes têm histórico de violência, agressividade, falta de respeito com os colegas de turma, e em alguns casos com os professores e os funcionários.

"Ela não faz o que pede, não faz o que é mandado [...] ela xinga, responde, depende do estresse". (Participante 01).

"Ele não tem problema com a professora, mas, a professora não confia nele". (Participante 03).

"Ele fala que responde a professora porque ela maltratava ele por causa da cor e da necessidade especial". (Participante 05)

"Ele responde o professor [...] ele irrita elas, vai brincar e é só confusão, eu passo a maior parte do tempo com ele na escola”. (Participante 06).

Em relação aos amigos na escola, apenas um (1) relata que seu filho tem amigos na escola e que amizade é bem construída e duradoura, contudo, todos os demais relatam que seus filhos têm poucos ou nenhum amigo na escola, e quando consegue conquistar tal amizade, não é duradoura. Esse curto tempo de amizade, segundo os responsáveis, se dá pela oscilação de comportamento dos adolescentes.

"Ela fala com todos, mas quando se estressa briga, xinga e bate". (Participante 01).

"Ele não tem amigos na escola, a escola estava reclamando que ele briga com os outros". (Participante 02).

"Ele não tem amigos na escola, briga com os colegas e é violento se alguém tira brincadeirinha ou se ele não gostar de algo". (Participante 03).

Nessa perspectiva, a amizade como um relacionamento entre pessoas de forma íntima, pessoal e privado, sem a imposição de valores ou normas culturais, desse modo, o TC apresenta muitas dificuldades de se relacionar com outras pessoas, e quando isso acontece, normalmente é marcado por brigas, desentendimentos, violência e/ou agressão, dificultando na construção da amizade (Fehr. 1996; Dias, 2012).

De acordo com o estudo de Souza et al (2021), quando os adolescentes possuem um adoecimento mental, é possível que eles fiquem somente em suas casas, sem contato com outras pessoas podendo sofrer rupturas totais ou parciais das ocupações que são realizadas diariamente. Sendo a escola, um local de desenvolvimento e trocas sociais. 
Em relação a assiduidade dos adolescentes na escola, os responsáveis demonstram que vão regularmente, e que gostam de ir. Já em relação aos problemas dentro da escola, quatro (4) já foram suspensos ou tiveram pequenas advertências e um (1) já foi expulso da escola.

Vários autores pontuam a importância da escola para o desenvolvimento social de adolescentes com TC, pois a escola é um ambiente que possibilita experiências sociais positivas ou negativas. Atrelado a isso, os autores falam que o comportamento desses adolescentes dentro da escola, que por vezes são reconhecidos como "alunos problemas" por apresentar uma conduta agressiva, não respeitar regras e comandos e não conseguir ter um rendimento escolar similar aos outros da turma, pode dificultar a participação desses adolescentes no ambiente escolar (Bordin, \& Offord, 2000; Papalia, Olds, \& Fedman, 2006; Silva, 2008).

Assim, em relação ao desempenho dos adolescentes na escola, foi relatado no questionário que todos os adolescentes têm dificuldade de aprender e/ou acompanhar os outros alunos da classe, fazendo que por vezes haja a repetição do ano escolar. Foi externado pelos responsáveis, a falta de preparação dos professores em lidar com o comportamento dos adolescentes ou a disponibilidade de mudar a metodologia de sala para incluir esses alunos.

"Ele não aprende, olha que escola divide alunos bons e alunos especiais". (Participante 02).

"Ele gosta de ir para escola, mas reclama que não faz nada na sala". (Participante 03).

"Ele não aprende, em casa dá trabalho para pegar no caderno, eu compro caça palavras e ele não faz". (Participante 06).

“Ela não consegue aprender". (Participante 07).

O TC, na maioria dos casos, está associado ao baixo rendimento escolar e a dificuldade de aprendizagem, além de que a falta de relacionamento com os demais colegas dificulta esse processo. Assim, os autores afirmam que é necessária a preparação da escola, dos alunos e dos funcionários, para lidar com essa situação, capacitando e orientando para compreensão do problema, melhorando as relações sociais e evitando a exclusão desse aluno (Bordin, \& Offord, 2000).

Dessa forma, participação social na escola, é prejudicada a presença de um comportamento desviante, com falta de respeito e impulsividade, fazendo com que o adolescente não construa laços sociais dentro do ambiente escolar, dificultando sua interação nesse ambiente e seu processo de aprendizagem.

\subsection{Participação social: Comunidade}

Este último tópico do estudo irá se preocupar com a participação social dos adolescentes com TC dentro da comunidade em que está inserido e como se desenvolve suas relações sociais dentro desse ambiente. $\mathrm{O}$ termo comunidade pode assumir diversos significados, mudando com o período histórico e com a vertente teórica-científica, mas nesse texto, ela assume o significado de um espaço de coletividade, relações de pessoas em um grupo, com segurança, confiança, amizade, conforto, apoio e um lugar de diversidade social, como um ambiente positivo para o fortalecimento das relações sociais (Oliveira, et al., 2013).

Assim, no desenvolver desse texto o termo comunidade não estará tão presente, assumindo como sinônimos os termos "vizinhos e/ou vizinhança e amigos" para facilitar a compreensão.

Nessa parte do questionário, as perguntas foram direcionadas a interação dos adolescentes com a vizinhança. Assim, três (3) responsáveis afirmaram que os adolescentes tinham um bom relacionamento, um bom diálogo e uma interação significativa com os vizinhos, já cinco (5) dos responsáveis afirmaram que não existe contato e interação de vizinhança com os adolescentes. 
Pode-se dizer que a falta de contato dos adolescentes com a vizinhança é pelo seu comportamento agressivo, violento, e de impulsividade, fazendo com que os responsáveis às vezes não permitam que os adolescentes saíssem na rua, ou se envolvam em atividades sociais.

Aqueles que não estabelecem um bom relacionamento com os vizinhos,

"Nenhum, é isolado dentro de casa, quando sai de casa briga". (Participante 06)

"Não, ele não se relaciona bem, ele já ameaçou os vizinhos". (Participante 03)

Os que estabelecem um bom relacionamento,

“Tem um bom relacionamento com os vizinhos, ele sai na rua, conversa...". (Participante 05)

A relação social é um fator de grande importância para o desenvolvimento humano, principalmente na participação social e no processo de construção de autoconhecimento e identidade individual. Os adolescentes com TC apresentam vários prejuízos psicoemocionais e de comportamento que prejudicam diretamente na efetivação da relação social (Mello, \& Texeira, 2012; Almeida, et al, 2014).

Assim, quando perguntados se os adolescentes estavam envolvidos em programas sociais, seis (6) responderam que não, apenas um (1) respondeu que o adolescente se envolve nesses tipos de programas, como: ir à festa, jogar bola e brincar na praça.

Já em relação à participação dos adolescentes em atividades na vizinhança, apenas dois (2) dos sete (7) responderam que eram engajados nesses tipos de atividades, como: patrulha mirim e grupos religiosos, os demais externam que os adolescentes não têm interesse nas atividades desenvolvidas na vizinhança e que não há confiança dos responsáveis em deixar os adolescentes saírem sem supervisão.

Foi relatado que esse não envolvimento dos adolescentes em programas sociais, atividades da vizinhança e interação com os vizinhos, se dá pela oscilação de humor dos adolescentes, causando nos responsáveis um comportamento superprotetor, que priva os adolescentes dessas experiências sociais.

"Não, eu não deixo ela sair de casa". (Participante 01).

"Não, ele só sai em passeios do CAPS. [...] e só sai comigo". (Participante 02).

"[..] Tem a patrulha mirim, mas o pessoal já não tem paciência”. (Participante 06).

"Ele sai com os amigos para festa e jogar bola". (Participante 04).

O sujeito no processo de construção de identidade marcado pela adolescente, deve se permitir estar inserido em vários lugares, com diferentes culturas, pessoas e comportamentos, desse modo, essa trajetória de autoconhecimento encontra-se interrompida no adolescente com TC por interferência direta dos responsáveis (Fernandes, K. \& Zanelli, J., 2006).

No que diz respeito aos amigos na vizinhança, cinco (5) responsáveis responderam que os adolescentes contêm poucos ou nenhum amigo na vizinhança, e quando estabelece algum tipo de amizade, não tem uma duração, por apresentar um comportamento violento e agressivo, já os outros dois (2) afirmaram que esses adolescentes tem vários amigos, mesmo existindo as oscilações de comportamento.

"Ela tem amizades de muito tempo. [...] se alguém não concordar com ela, ela se estressa, xinga, bate e mete o pau". (Participante 01) 
"Não dura nem 3 meses com os amigos. [...] Ele bate, pega no pescoço". (Participante 03)

"Não, ele não tem amigos. [..] se irrita, briga e bate neles". (Participante 06).

Já em relação ao comportamento de quebra de regras sociais ou particulares da vizinhança, apenas um (1) relatou a existência de delitos relacionados ao ato de pichar o muro e invadir patrimônio público e privado.

"Ele já pixou o muro e pula o muro dos outros e já pulou o da escola". (Participante 03).

Como pontuado no tópico anterior, o adolescente com TC tem dificuldades gritantes em relação a estabelecer laços sociais duradouros e contínuos, comportamentos como esse, de: não estabelecer um relacionamento social, não estabelecer interações sociais e ter ações que vão de encontro com as regras sociais, é um comportamento típico de adolescentes com esse diagnóstico (Dias, 2012).

Dessarte, é notório que a participação social dos adolescentes com TC dentro do ambiente comunitário se constitui de forma insatisfatória, e essas problemáticas estão diretamente relacionadas ao comportamento. Atrelado a isso, existe a privação dos responsáveis em relação à participação dos adolescentes nesse meio, desse modo, o desempenho ocupacional no que diz respeito à participação social na comunidade, tem perdas muito significativas para esses adolescentes.

\section{Considerações Finais}

Depois da análise e interpretação qualitativa dos dados verificou-se que a principal dificuldade para a efetivação de um bom desempenho ocupacional em relação à participação social de adolescentes com transtorno de conduta, se dá pela oscilação de comportamento, evidenciando a agressividade e a violência.

Outra característica que influencia diretamente nesse processo, é a dificuldade dos adolescentes firmarem laços sociais e de relacionamentos com terceiros e externar empatia e afeto, dificultando na construção de uma rede social efetiva e prejudicando diretamente a ocupação no que se refere à participação social.

Além desses comportamentos, várias outras características podem colaborar inteiramente, como a mentira, a impulsividade, falta de limites e a não aceitação das regras sociais. Sendo assim, todas essas particularidades estão totalmente conectadas para a não efetivação da participação social do adolescente com Transtorno de Conduta, sendo características comuns em qualquer um dos pólos, seja ele; família, escola e/ou comunidade.

No entanto, sugerem-se estudos futuros que envolvam maior número de participantes e diferentes metodologias, fazendo com que o adolescente com tal diagnóstico seja um dos contribuintes ativo no processo de aquisição dos dados, além de diferentes formas de aquisição de material, como: entrevista, grupo focal, história oral, e com isso ter um estudo mais aprofundado e detalhado sobre a temática.

A participação social é um fenômeno complexo que necessita de estudos mais aprofundados e discussões críticas dentro do cenário científico, desta forma, compreende-se que o presente estudo contribui para o avanço do conhecimento em relação ao desempenho ocupacional de adolescentes com transtorno de conduta em relação a sua participação social, além de proporcionar reflexões acerca de intervenções terapêuticas na atenção psicossocial infantil que visem à ampliação e o fortalecimento da participação social deste público.

Tornam-se necessárias mais pesquisas direcionadas ao público com transtorno de conduta, a fim de investigar de forma mais profunda as problemáticas relacionadas ao seu desempenho de atividades cotidianas e estruturar intervenção terapêutica com esse público. 


\section{Referências}

Agostini, V., \& Santos, W. (2017) Transtorno desafiador de oposição e suas comorbidades: um desafio da infância à adolescência. Psicologia.pt (online). https://www.psicologia.pt/artigos/ver_artigo.php?transtorno-desafiador-de-oposicao-e-suas-comorbidades-um-desafio-da-infancia-aadolescenc ia\&codig o=A1 $175 \&$ area $=\mathrm{d} 5$

Almeida, L. (2013). Análise funcional em um estudo de caso de transtorno desafiador de oposição e transtorno de conduta. Revista Científica da Faculdade de Educação e Meio Ambiente, 5(2), 15-35.

Alves, Z. \& Silva, M. (1992). Análise qualitativa de dados de entrevista: uma proposta. Paidéia, (2).

American Psychiatric Association. (2013). Diagnostic and Statistical Manual: Conduct Disorder.

AOTA. (2015). Estrutura da prática da Terapia Ocupacional: domínio \& processo (3a ed.), Rev Ter Ocup Univ São Paulo, 26 (edição especial), 1-49.

Aranha, M (2000). Inclusão Social. In: E. J. Manzini (Org.) Educação Especial: Temas Atuais. Unesp. Marília-Publicações.

Araújo, F. et al. (2017). A afetividade na relação familia e escola: reflexões sobre o processo de ensino e aprendizagem. In Anais Eletrônicos do IV Congresso Nacional da Educação, João Pessoa - $\quad$ PB. 2017. https://editorarealize.com.br/revistas/conedu/trabalhos/TRABALHO_EV07 3_MD1_SA18_ID770_19092017003741.pdf.

Barletta, J. (2011). Avaliação e intervenção psicoterapêutica nos transtornos disruptivos: algumas reflexões. Rev. bras. ter. cogn., 7 (2), 25-31.

Bordin, I. \& Offord, D. (2000). Transtorno da conduta e comportamento anti-social. Revista Brasileira de Psiquiatria. 22(2), 12-5.

Chapparo, C. \& Ranka, J. (1997). The Occupational Performance Model (Australia): A description of constructs and structure. Sidney, Australia: The University of Sidney, 1-22.

Codea, J. \& Beresford, H. (2004). O adolescente com transtorno de conduta: um estudo filosófico no âmbito da psicologia educacional e esportiva. Psicologia Escolar e Educacional, 8(1), 67-74.

Dias, L. Considerações acerca do transtorno de conduta. (2012). Monografia (Especialização em psicologia) - Universidade Federal do Rio Grande do Sul, Porto Alegre.

Diehl, A.A. \& Tatim, D.C. (2004). Pesquisa em ciências sociais aplicadas: métodos e técnicas. Pearson Prentice Hall.

Fehr, B. (1996). Friendship processes. Sage.

Fernandes, K. \& Zanelli, J. (2006). O processo de construção e reconstrução das identidades dos indivíduos nas organizações. Rev. adm. contemp., 10(1), 55-72.

Fernandes, M. E. (1991). Memória Camponesa. Anais da 21 ${ }^{a}$ Reunião Anual de Psicologia, SPRP.

Ferriolli, S., Marturano, E. \& Puntel, L. (2007). Contexto familiar e problemas de saúde mental infantil no Programa Saúde da Família. Rev Saúde Pública, 41(2) 251-259.

Leitão, S., Fortunato, G. \& Freitas, A. (2006). Relacionamentos interpessoais e emoções nas organizações: uma visão biológica. RAP, $40(5), 883-907$.

Machado, J., Caye, A., Frick, P. \& Rohde, L. (2015). Principais mudanças nos transtornos de crianças e adolescentes. In: Silva, F. Tratado de Saúde Mental da Infância e Adolescência da IACAPAP(p. 1-23).

Maluf, A. (2010). Novas modalidades de família na pós-modernidade. São Paulo: Atlas.

Melo, D. et al (2016). Transtorno de conduta: influência de fatores psicofisiológicos e socioambientais na personalidade de menores no envolvimento de atos infracionais. Psicologia.pt (online). https://www.psicologia.pt/artigos/textos/TL0394.pdf.

Mello, E. \& Teixeira, A. (2012). A interação social descrita por Vigotski e a sua possível ligação com a aprendizagem colaborativa através das tecnologias de rede. In Anais Eletrônicos do IX Seminário de pesquisa em Educação da Região Sul, UFRGS. http://www.ucs.br/etc/com ferencias/index.php/anpedsul/9anpedsul/paper/viewFile/6/871

Oliveira, S. et al. (2013). Discussões sobre o conceito de comunidade relacionado à atuação do enfermeiro: relato de experiência. av.enferm, 31(1), 133-140.

Papalia, D., Olds, S. \& Fedman, R. D. (2006). Desenvolvimento Físico e Cognitvo na Terceira Infância. (8a ed.), Artmed.

Pinheiro, M., et al. (2004). Transtorno Desafiador de Oposição: uma revisão de correlatos neurobiológicos e ambientais, comorbidades, tratamento e prognóstico. Rev. Bras. Psiquiatr. 26((4), 273-6.

Santos, T. C. V., Ary, M. L. \& Calheiros, D. S. (2021). Vínculos familiares dos idosos institucionalizados. Research, Society and Development 10(12), e194101220246.

Silva, A. (2008). Mentes Perigosas: o psicopata mora ao lado. Fontanar.

Souza, M. A., Lins, A. E., Acácio, M., Costa, L. F., \& Ary, M.L. (2021). Fatores associados ao comportamento autolesivo em adolescentes atendidos em um Centro de Atenção Psicossocial do Nordeste do Brasil. Research, Society and Development, 10 (11), e518101119744. https://doi.org/10.33448/rsd-v10i11.19744 
Research, Society and Development, v. 10, n. 12, e301101220430, 2021

(CC BY 4.0) | ISSN 2525-3409 | DOI: http://dx.doi.org/10.33448/rsd-v10i12.20430

Squillaci, M. \& Benoit, V. (2021). Papel de Traços Calosos e Não Emocionais (CU) no Desenvolvimento de Jovens com Transtornos Comportamentais: Uma Revisão Sistemática. Int. J. Environ. Res. Public Health, 18, 4712. https://doi.org/10.3390/ijerph18094712

Wieczorkievick, A. \& Baade, J. (2020). Família e escola como instituições sociais fundamentais no processo de socialização e preparação para a vivência em sociedade. Revista Educação Pública, 20(20). https://educacaopublica.cecierj.edu.br/artigos/20/19/familia-e-escola-como-instituicoes-sociais-fundamentais-noprocesso-de-socializacao-e-preparacao-para-a-vivencia-em-sociedade 